\title{
BREVE CONSIDERAÇÃO SOBRE INTERTÍCIOS DE TREVAS GREGAS
}

\section{Brief consideration about the darkness Greek intersticies}

Imaculada Kangussu ${ }^{1}$

\author{
Ao Túlio e ao Gilson, que me ajudaram \\ a discorrer sobre o paradoxo.
}

\section{Resumo}

Este artigo objetiva reportaras abordagens de Borges sobre o paradoxo da interminável corrida entre Aquiles e a tartaruga, criado porZenão de Eléia. Minha hipótese é que mostrando os limites da racionalidade lógica, Borges nos ajude a entender melhor a filosofia.

Palavras-chave: Continuidade, Infinito; Abismo; Descontinuidade; Borges; Carroll.

\section{Abstract}

This article aims to report Borges approaches concerning the paradox of the interminable racecourse between Aquiles and the tortoise, created by Zenon of Elea. My hypothesis is that, showing the limits of logical rationality, Borges helps us to understand philosophy better. Keywords: Continuous; Infinite; Abyss; Discontinuity; Borges, Carroll.

1 Doutoura em Filosofia. Professora de Filosofia da Universidade Federal de Ouro Preto, Instituto de Filosofia Artes e Cultura, Departamento de Filosofia. Rua Coronel Alves, 55 Centro 35400-000 - Ouro Preto, MG Brasil Telefone: (31) 3559-1728 Fax: (31) 355-91732. E-mail: defil@ifac.ufop.brｌecakangussu@hotmail.com 
O paradoxo inventado por Zenão de Eléia, discípulo de Parmênides, a respeito da corrida entre Aquiles e a tartaruga mereceu dois comentários de Jorge Luis Borges, "A perpétua corrida de Aquiles e da tartaruga" e "Avatares da tartaruga", ambos publicados em Discussión $(1932)^{2}$.

No primeiro texto, a fábula de Zenão é assim apresentada: “Aquiles, símbolo de rapidez, tem de alcançar a tartaruga, símbolo de morosidade. Aquiles corre dez vezes mais rápido que a tartaruga e lhe dá dez metros de vantagem. Aquiles corre esses dez metros, a tartaruga corre um; Aquiles corre esse metro, a tartaruga corre um decímetro; Aquiles corre esse decímetro, a tartaruga corre um centímetro; Aquiles corre esse centímetro, a tartanuga um milímetro; Aquiles corre esse milímetro, a tartaruga um décimo de milímetro, e assim infinitamente, de modo que Aquiles pode correr para sempre sem alcançá-la" (OC, p.261).

Borges não pretende explicar o fabuloso paradoxo. O prólogo do livro informa ao leitor que as páginas sobre "A perpétua corrida de Aquiles e da tartaruga" não solicitam "outra virtude que a de sua profusão de dados" (OC, p.185). No texto, são enumeradas duas versões e seis refutações do paradoxo. Cronologicamente, a primeira refutação é a de Aristóteles, a ela seguiram as de Hobbes, Stuart Mill, Henri Bergson, Russell e William James, escreve Borges. ${ }^{3}$ Através da apresentação do paradoxo, pode-se perceber que a astúcia da falácia está em introduzir o infinito no finito, a série de números no espaço da corrida. A série de números naturais é infinita, e o intervalo que separa os números fracionados é eternamente divisível. Um não continua no outro, ao contrário, um infinito os separa. Através da continuidade, a distância é intransponível. Há, por exemplo, um infinito 4,99999... que nunca chega a 5. Considerando suas frações, nenhum número tem sucessor ou predecessor imediato. Ir de um número a outro significa saltar sobre o abismo sem fundo da descontinuidade. Ou, nas palavras de Borges, uma "ilimitada queda em precipícios cada vez mais minúsculos” (OC, p.263).

2 BORGES, "La perpetua carrera de Aquiles y la tortuga" e "Avatares de la tortuga", en Discusión. Traduzidos por Josely Vianna Baptista, os textos foram publicados em BORGES, Obras completas, volume I. A obra será por nós citada como OC.

3 Borges cita MILL, Sistema de lógica, livro V, capítulo 7; BERGSON, Ensaio sobre os dados imediatos da consciência; RUSSEL, Introduction to Mathematical Philosophy e Our Knowledge of the External World; JAMES, Some Problems of Philosophy.

Revista de Filosofia, Curitiba, v. 16 n.19, p. 85-92, jul./dez. 2004. 
A única refutação considerada por Borges à altura do paradoxo de Zenão - visto como uma jóia cuja limpidez "não exclui o impenetrável” - é a formulada por Russell. "A única de inspiração condigna do original, virtude que a estética da inteligência está reclamando" é apresentada em "livros de uma lucidez desumana, insatisfatórios e intensos" (OC, p.264). Russell assinala que a série dos números naturais é infinita e pode, por sua vez, desdobrar-se em séries infinitas: há uma série infinita de números pares, de números ímpares ou de múltiplos de 54, por exemplo. A parte não é menor do que o todo. E a série de números fracionados não é sequer ordenável, assim como a série de pontos no espaço, de acordo com Georg Cantor. "A quantidade precisa de pontos que há no universo é a que há em um metro do universo, ou num decímetro, ou na mais profunda trajetória estelar" (OC, p.265). Segundo James, reporta Borges, a verdadeira dificuldade, que as explicações de Russel eludem, diz respeito à categoria crescente do infinito. Segundo Borges, a verdadeira dificuldade diz respeito à própria palavra "infinito", "palavra (e depois conceito) angustiante que engendramos com temeridade e que, uma vez consentida num pensamento, explode e o mata" (OC, p.266). A elucidação dos abismos que pululam no paradoxo só é possível, conclui Borges, se aceitarmos a idealidade de nossos conceitos de espaço e tempo. É precisamente o caráter de idealidade das explicações filosóficas que aflora no comentário borgeano atravessando, com indisfarçável sorriso, a erudita enumeração das leituras do paradoxo, que pululam na história do espírito.

O assunto é retomado em "Avatares da tartaruga". Borges inicia o texto com a afirmação de que "há um conceito que corrompe e transtorna os outros. Não falo do Mal cujo limitado império é a ética; falo do infinito" (OC, p.273). O autor confessa ter pensado compilar, em uma Biografia do infinito, a história movediça desse conceito. A esse livro ilusório pertenceriam as páginas cujo propósito é registrar alguns avatares do paradoxo de Aquiles. O primeiro é encontrado em Aristóteles (Física, VI, 9) que refuta o argumento de Zenão, "com brevidade talvez desdenhosa" (OC, p.274), mas a ele remonta na formulação do famoso argumento do terceiro homem. Borges relembra que, contra a doutrina platônica das idéias, segundo a qual as coisas sensíveis seriam meras aparências temporais de idéias eternas, Aristóteles argumenta que se um homem que existe no mundo fenomênico corresponde à idéia absoluta de Homem, será preciso postular uma terceira idéia de homem que con-

Revista de Filosofia, Curitiba, v. 16 n.19, p. 85-92, jul./dez. 2004. 
tenha os dois homens anteriores, o do mundo dos fenômenos e o do mundo das idéias. "Há, pois, um terceiro homem diferente dos homens particulares e da idéia. Há ao mesmo tempo um quarto, que estará na mesma relação com este e com a idéia de homens particulares; depois um quinto e assim infinitamente" (OC, p.274-275). Borges assinala que se Zenão recorre ao vertiginoso regressus in infinitum para negar 0 movimento, seu refutador Aristóteles faz o mesmo para negar as idéias universais propostas por Platão. A disposição do próprio Borges a respeito de Platão aparece em outro texto onde o escritor discorre sobre a necessidade de se ter algum conhecimento sobre "o imóvel e terrível museu dos arquétipos platônicos. Não sei se foi visto por olhos mortais" pondera, "ou se o grego remoto que o concebeu chegou a representá-lo alguma vez, mas pressinto nele algo de museu: quieto, monstruoso e classificado... Trata-se de imaginação pessoal da qual pode prescindir o leitor; do que não convém que prescinda é de alguma informação geral sobre esses arquétipos platônicos, ou causas primordiais, ou idéias, que povoam e compõem a eternidade". ${ }^{4}$

O próximo avatar enumerado aparece um século depois de Zenão, trata-se do proposto pelo sábio chinês Hui Tzu que argumentou ser interminável um bastão cortado pela metade a cada dia. A ele seguem Sexto Empírico que considera as definições inúteis, pois seria necessário definir cada palavra nelas utilizadas e depois definir a definição ${ }^{5}$, e "Agripa, o cético", que nega que algo possa ser provado já que toda prova requer uma prova anterior, ad infinitum (OC, p.275). Borges parece estar se referindo ao filósofo ligado a Pico della Mirandola, Heinrich Cornelius (1486-1535), que se dava o nome de Agrippa de Nettesheim, e escreveu De vanitate et incertitudine scientiarum, obra que refuta as ciências, com argumentos extraídos de Sexto Empírico.

Se até esse ponto o infinito mise en abyme serviu para negar, Borges ressalta que Tomás de Aquino o utiliza para afirmar que Deus

4 BORGES. "História da eternidade", em História da eternidade, (OC, p.390). No prólogo, Borges se desculpa por não ter entendido, "lendo Schopenhauer e Erígena", que as Formas platônicas "são vivas, poderosas e orgânicas" (OC, p.385). Neste texto reaparece o paradoxo de Zenão e a refutação de Russell (OC, p.388), que retorna, de novo, acompanhando as proposições de Cantor nas páginas sobre "A doutrina dos Ciclos", em História da eternidade, (OC, p.426ss).

5 Borges faz uma analogia com o que Byron escreve de Coleridge, em Don Juan: "I wish he could explain His Explanation" (OC, p.275).

Revista de Filosofia, Curitiba, v. 16 n.19, p. 85-92, jul./dez. 2004. 
existe. O escritor se refere a um dos caminhos apresentados na Summa Theologiae para provar a existência de Deus, o caminho da causa eficiente. De acordo com Tomás de Aquino, "no mundo das coisas sensíveis, nos defrontamos com a existência de uma ordem de causas eficientes. Não é caso conhecido de uma coisa que seja a causa eficiente de si mesma, porque, para tanto, deveria ser anterior a si mesma, o que é na verdade é impossível" (Summa Theologiae, I, 2,3). Entretanto, anular a causa significa anular o efeito, e como as coisas existem é necessário aceitar que existam causas eficientes. Se fosse possível ir ao infinito das causas, julga o teólogo, não haveria causa primeira, e com astucioso ardil retórico conclui: se não houvesse causa eficiente primeira, nesse caso não haveria as coisas o que, evidentemente, é falso. Por isso, é preciso aceitar a existência de uma causa eficiente primeira, "que será a divindade. Tal é a prova cosmológica" (OC, p.276). Tomás de Aquino pretende achar uma causa que produz e não é produzida, a causa incausada, que se existe, identifica-se com o que é chamado de "Deus". A existência de algo que seja causa sui precisa ser admitida, pois a ausência da causa primeira significa a queda no infinito. Borges considera que Aristóteles e Platão prefiguram a prova cosmológica e que Leibniz a redescobre.

Em seguida, nos "Avatares da tartaruga", são apresentados três argumentos análogos, que recorrem ao regressus in infinitum: os de Hermann Lotze, de Bradley e de Lewis Carroll. "Lotze interpõe os abismos periódicos de Zenão entre a causa e o efeito; Bradley, entre o sujeito e o predicado; Lewis Carrol entre a segunda premissa do silogismo e a conclusão" (OC, p.276). Deixo ao leitor curioso a tarefa de buscar os dois primeiros no texto borgeano e passo ao terceiro.

O texto de Carroll, "O que a tartaruga disse a Aquiles", tem início quando o veloz corredor finalmente alcança a tartaruga e confortavelmente se senta em seu casco. "Então você chegou ao fim de nossa corrida?", pergunta a tartaruga. "Mesmo que ela de fato consista em uma infinita série de distâncias? Eu pensei que alguém que afetasse grande sabedoria, ou um outro, houvessem provado que isso não poderia ser feito". ${ }^{6}$ Aquiles responde que as distâncias foram ficando cada vez menores e isso permitiu sua chegada. A lenta companheira lhe propõe então um novo problema, no qual infinitas distâncias seriam acrescentadas. O guerreiro grego aceita o desafio "e tira do capacete (poucos guerreiros

${ }^{6}$ CARROL, Lewis. "What the tortoise said to Achilles", p. 278.

Revista de Filosofia, Curitiba, v. 16 n.19, p. 85-92, jul./ dez. 2004. 
possuíam bolso naquele tempo) um enorme caderno e um lápis". A tartaruga apresenta o seguinte raciocínio, baseado na "bela primeira proposição de Euclides" ${ }^{7}$ :

(A) Duas coisas iguais a uma terceira são iguais entre si.

(B) Os dois lados de um triângulo são iguais a MN.

(Z) Os dois lados desse triângulo são iguais entre si.

Aquiles considera garantida a verdade do raciocínio, e um leitor incapaz de perceber isso, considera ainda, "agiria sabiamente abandonando Euclides e indo jogar futebol". ${ }^{8}$ A tartaruga discorda da conclusão - uma tartaruga jogando futebol, devaneia Aquiles. Ela introduz uma condição: se as proposições A e B são verdadeiras, Z é verdadeira; e exige que ela seja acrescentada. "O que mais tem escrito neste teu caderno?" Pergunta a Aquiles, "alguns memorandos das batalhas nas quais eu me distingui", responde o guerreiro. "Muitas folhas brancas, eu vejo", registra animada a tartaruga. "Nós podemos precisar de todas elas", continua, "agora escreva conforme eu ditar":

(A) Duas coisas iguais a uma terceira são iguais entre si.

(B) Os dois lados de um triângulo são iguais a $\mathrm{MN}$.

(C) Se A e B são verdadeiras, $Z$ é verdadeira.

(Z) Os dois lados desse triângulo são iguais entre si.

Aquiles observa que, se a tartaruga aceitar A, B e C deve também aceitar Z, entretanto ela interpola uma nova proposição hipotética: (D) Se A, B, e C são verdadeiras Z é verdadeira. Aquiles anota a nova interpolação, e satisfeito, comenta: "por fim chegamos ao final desta corrida ideal! Agora que você aceita A, e B, e C, e D, obviamente aceita Z". Mas a tartaruga retruca que para garantir a verdade é preciso afirmar que: (E) Se A, B, C e D são verdadeiras, Z é verdadeira. Aquiles concorda, "e havia um toque de tristeza em sua voz". E aqui o narrador abandona a dupla e quando a reencontra, alguns meses depois, o caderno de Aquiles estava quase cheio. Segundo Carroll $^{9}$, a tartaruga propunha en-

Ibidem.

8 CARROLL, Lewis. "What the tortoise said to Achilles", p. 279. São da mesma página as próximas citações.

9 CARROL, Lewis. "What the tortoise said to Achilles", p. 280.

Revista de Filosofia, Curitiba, v. 16 n.19, p. 85-92, jul./dez. 2004. 
tão - "considerando o tanto de instrução que este colóquio fornecerá para os lógicos do século XIX" - uma curiosa inversão dos papéis: que Aquiles mudasse seu nome para Thaught-Us ("pensamos nós", que em inglês soa parecido com "tortoise", tartaruga) e que permitisse a ela adotar o nome de A Kill-Ease (algo como "um curso tranqüilo", e que no original se assemelha ao nome de Aquiles). "Carroll observa que o paradoxo do grego comporta uma infinita série de distâncias que diminuem, e que no proposto por ele as distâncias aumentam" (OC, p.277).

Descartes, Hobbes, Leibniz, Mill, Renouvier, Georg Cantor, Gomperz abordaram o inesgotável paradoxo de Zenão, registra Borges, e apresenta então a magnífica hipótese de que talvez o vertiginoso regressus in infinitum seja aplicável a todos os raciocínios. "A estética: tal verso nos comove por tal motivo, tal motivo por outro motivo... Ao problema do conhecimento: conhecer é reconhecer, mas é preciso ter conhecido para reconhecer..." (OC, p.278). O escritor adverte para um duplo perigo: "é arriscado pensar que uma coordenação de palavras (as filosofias não são outra coisa) possa se assemelhar muito ao universo. Também é arriscado pensar que dessas coordenações ilustres, alguma ao menos de modo infinitesimal - não se assemelhe um pouco mais do que outras". Borges conclui o texto lembrando que nós sonhamos o mundo como sendo "resistente, misterioso, visível, ubíquo no espaço e firme no tempo; mas aceitamos em sua arquitetura tênues e eternos interstícios de desrazão para saber que é falso" (OC, p.278).

Com elegante sobriedade, as fendas existentes nos raciocínios lógicos são apresentadas nos textos sobre a corrida entre Aquiles e a tartaruga. Fica evidente que a ligação entre um pensamento e outro, modo de articular o discurso da razão, salta sempre sobre alguns abismos de descontinuidade.

Para concluir, lembro dois filósofos que também duvidaram do discurso lógico. Nas reflexões de Walter Benjamin, o lugar da verdade é o lugar do inexprimível, do que aparece no discurso como irredutível cesura. "No inexprimível manifesta-se a sublime violência da verdade"10. Não podendo, obviamente, ser expresso, o inexprimível aparece como rachadura que destrói a falsa totalidade do discurso e, com isso, estabelece seu momento de verdade. Salvador-destruidor, ele aniquila a pretensão ao absoluto, e mostra que o mundo verdadeiro só pode aparecer

10 BENJAMIN. "'Les affinités electives' de Goethe”, Oeuvres choisies, p.162.

Revista de Filosofia, Curitiba, v. 16 n.19, p. 85-92, jul./dez. 2004. 
em fragmentos, como um torso. É condição de possibilidade para a expressão verdadeira a aniquilação da totalidade falsa, o abandono do discurso reto, claro e sem fendas. Antes de Benjamin, abrindo brechas para as possibilidades de outros modos do pensamento, distintos do lógico-linear que séculos de tradição logocêntrica nos apresentam quase como sinônimo do próprio pensar, Peirce, em The Essence of Reasoning (1893), foi bastante claro: a análise da proposição em sujeito e predicado pode representar toleravelmente a maneira pela qual os arianos pensam, porém, ele não aceita que seja esse o único modo de pensar, ou que seja sequer o mais claro ou mesmo o mais eficiente.

Borges não é um cético, apenas desdenha a lógica, ou melhor, os limites por ela impostos ao pensamento. Com isso amplia o espectro da cognoscibilidade, através de caminhos que os lógicos possivelmente acusariam de obscurantistas, ou poéticos. A apresentação que ele faz do mundo é uma espécie de jogo de reflexos com espelhos que se deslocam. "Sua plenitude é precisamente a de um espelho, que aparenta estar cheio e está vazio; é um fantasma que nem sequer desaparece, porque não tem nem ao menos a capacidade de cessar. O fundamental são as formas" (OC, p.390).

\section{Referências}

BORGES, Jorge Luis. Avatares de la tortuga. Discusión. Buenos Aires: Emecé, 1989.

. La perpetua carrera de Aquiles y la tortuga. Discusión. Buenos Aires: Emecé, 1989.

. Obras Completas. São Paulo: Globo, 1998. v. 1.

CARROLL, Lewis. What the tortoise said to Achilles. Mind,n. 4, p. 278-280, 1895.

Recebido em - Recieved in: 07/07/ 2004 Aprovado em - Approved in: 22/08/2004 